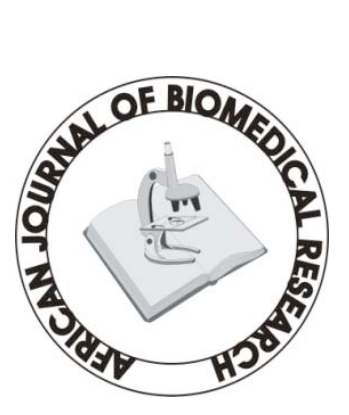

Full-text available at http://www.ajbrui.com http://www.bioline.br/md http://www.ajol.com
Received:

January 2008

Accepted (Revised):

June 2008

Published

Septemeber 2008
Full Length Research Article

\section{Anti-oxidant vitamins, nitric oxide and acute phase proteins in Nigerian Cigarette Smokers}

\author{
*Arinola O.G and Akinosun A.M \\ Department of Chemical Pathology and Immunology, \\ College of Medicine, University of Ibadan, Nigeria
}

\section{ABSTRACT}

It is established that there is increased risk of developing heart disease, chronic bronchitis, emphysema, lung cancer and infections in cigarette smokers. However specific mechanisms whereby cigarette smoking causes these are not fully understood. The present study provided information to explain above observation by measuring plasma levels of caeruloplasmin, alpha-2-macroglobulin, nitric oxide (NO) and vitamins $\mathrm{C}$ and $\mathrm{E}$ in Nigerian cigarette smokers and non-cigarette smokers. The mean values of antioxidant vitamins $\mathrm{C}$ and $\mathrm{E}$ were significantly lower while $\mathrm{NO}$ was not significantly reduced in the smokers compared with the controls. The level of alpha-2macroglobulin was significantly raised while caeruloplasmin was not significantly raised in smokers compared with controls. This study confirmed that inflammation is a common phenomenon in cigarette smokers and that significantly decreased levels of antioxidant vitamins $\mathrm{C}$ and $\mathrm{E}$ and raised level of caeruloplasmin might explain the development of cardiovascular diseases in cigarette smokers.

(Afr. J. Biomed. Res. 11: 291-295)

Key Words; Cigarette, Nigeria, oxidants, vitamins and acute phase reactants.

*Corresponding author: arinolaog@doctor.com,drarinolaog64@yahoo.com 


\section{INTRODUCTION}

Cigarette smoke is a complex mixture of thousands of compound containing relatively high concentrations of oxidants or pro-oxidants (Alberg, 2002), which are capable of initiating and enhancing lipid peroxidation and oxidizing pulmonary proteins (Pryor, 1997). Cigarette smoking also induces inflammatory response which is evident by the pulmonary accumulation of macrophages and neutrophils, and these activated phagocytes are capable of further generation of oxidants (Martin and Frei, 1997 ).These oxidants are reduced, quenched or neutralized by antioxidants (Young and Woodside, 2001 ). Cellular and tissue antioxidant defenses are enzymatic (superoxide dismutases, catalase and glutathione peroxidase), dietary micronutrients (vitamin $\mathrm{E}$, vitamin $\mathrm{C}$, beta carotene and selenium) and acute phase proteins (albumin and caeruloplasmin) (Young and Woodside, 2001). Vitamin $\mathrm{E}$ is well recognized for its role in maintaining membrane integrity (Dietrich et al, 2003) and protection from reactive $\mathrm{O}_{2}$ species which has been implicated in both carcinogenesis and arterial injury by ischemia (Dietrich et al, 2003 ). Vitamin C, Vitamin E, selenium, albumin and caeruloplasmin are immunoregulators (Duthie, 1999). Leucocytes vitamin C, plasma betacarotene, alpha-1-protease inhibitor and carotenoids have been shown to be reduced in smokers (Fehily et al, 1980). Others found that levels of vitamin $\mathrm{E}$ and selenium were not significantly reduced in smokers compared with non- smokers (Stryker et al, 1988). Since it is an established fact that cigarette smoke induces inflammation and contain oxidants/pro-oxidants (Pryor 1997, Alberg 2000), the purpose of this study is to determine the effects of smoking on micronutrients such as vitamins $\mathrm{C}$ and $\mathrm{E}$ (which serve as antioxidants), acute phase proteins such as caeruloplasmin and alpha macroglobulin (which serve as inflammatory agents) and NO. The outcome of this study may account in part for the increased risk of diseases and oxidant burden in cigarette smokers.

\section{MATERIALS AND METHODS}

\section{Study Population:}

A total of 58 apparently healthy male volunteers were recruited for this study. Each subject completed an extensive questionnaire regarding his medical histories, cigarette and drug usage histories, alcohol consumption, intake of nutrients supplements and demographics. These were divided into test group (Cigarette smokers) consisting of 28 males (23-64 years of age), who are with at least 4 years history of smoking and are still active smokers. The controls consist of age and sex matched non-smokers $(\mathrm{n}=30)$. All participants are civil servants living and working in Apata, Iddo Local Government Area, Ibadan, Nigeria. Selection was based on similarities in diets, socio-cultural behavior and educational standard. None of the participants is on multivitamin tablet or on any form of compulsory medication.

The brands of cigarette commonly smoked are Benson and Hedges, St Moritz, London Brown and London White. Consumers of alcoholic beverages or those on locally brewed drinks were excluded. Others excluded were those with high parasite densities, abnormal liver functions, pathogenic infections and abnormal renal functions as presented by blood, urine and stool tests as described in a standard text (Chessborough, 1994). Those that declined their consents and passive smokers were also excluded.

\section{Blood Collection:}

UCH/UI Ethical Committee approved the study before commencement. Also, informed consent was obtained from each participant before sample collection. Between $6.0-10.0 \mathrm{mls}$ of whole blood was collected by venepuncture without stasis from each subject into bottles containing lithium heparin, which was quickly transferred into ice pack in black water - proof polyethylene bag. Blood samples were centrifuged at 3,000 rpm for 5 minutes in an MSE Centrifuge in a working area with low intensity light.

\section{Determination of Vitamin C:}

Vitamin $\mathrm{C}$ was estimated using colorimetric 
method of Halliwell and Gutteridge (1995). To $2 \mathrm{ml}$ plasma in a centrifuge tube, $2 \mathrm{ml}$ of colour reagent was slowly added, mixed thoroughly, allowed to stand for 30 minutes at room temperature and centrifuged at 3,000rpm for 15 minutes. Blue coloured supernatant was carefully transferred into another test-tube with Pasteur pipette without disturbing the precipitate. The blank (distilled water instead of plasma) and standard were treated similarly as the plasma samples. For each batch of samples analyzed, a fresh blank and standard were prepared. Absorbance was read at 700nm wavelength using the blank to set zero. Concentrations of samples were extrapolated from standard calibration curve. Tocopherol and carotene were first extracted into xylene and extinction read at $460 \mathrm{~nm}$ to measure the carotenes. To correct for carotene, ferric chloride was added and absorbance read at $600 \mathrm{~nm}$.

\section{Determination of Vitamin E:}

Vitamin E was estimated using colorimetric method of Halliwell and Gutteridge (1995). 1.0ml of absolute ethanol was pipetted into glassstoppered test tube and $1 \mathrm{ml}$ of plasma was added into corresponding labeled tube with shaking to obtain protein precipitate. $1 \mathrm{ml}$ of reagent-grade xylene was added and the tubes were covered tightly and content mixed vigorously for 30 seconds. All tubes were centrifuged at 3000rpm for 5 minutes. $0.5 \mathrm{ml}$ of the xylene layer was extracted from each tube into corresponding labeled (light screened) tube. $0.5 \mathrm{ml}$ of a dipyridyl solution was added to each tube and mixed thoroughly. Blank was prepared by adding to $1.0 \mathrm{ml}$ of xylene, $0.5 \mathrm{ml}$ of alpha, alpha dipytidyl and to $0.1 \mathrm{ml}$ of ferric chloride hexahydrate solution. Using the blank, the spectophotometer was set to zero and absorbance was read at $460 \mathrm{~nm}$. To each tube, $0.1 \mathrm{ml}$ of ferric chloride hexahydrate solution was added and mixed thoroughly. Spectrophotometer was set to zero using the blank, and absorbance of both the sample and standard was read at $600 \mathrm{~nm}$. Solutions were freshly prepared with each batch of specimen.

Calculations:

Vitamin $\mathrm{E}=$

Absorbance at $600 \mathrm{~nm}-(0.40 \times$ absorbance at $460 \mathrm{~nm}$

Absorbance of standard at $600 \mathrm{~nm}$

0.40 is correction factor for interfering beta-carotene extract read at $460 \mathrm{~nm}$.

Determination of levels of acute phase proteins (Caeruloplasmin and alpha-2- macroglobulin):

The method of single radial immuno-diffusion was used (Salimonu et al, 1978). A volume of an optimally diluted mono-specific anti-serum was mixed with noble agar and poured on glass plate. Wells of equal diameter were cut in anti-serum agar mixture and fill with test or standard serum. The plates were incubated at $37^{\circ} \mathrm{C}$ after which the diameters of the precipitin ring were measured with micrometer eyepiece. In each case, the standard curve was plotted as diameter of precipitin ring versus percentage concentration.

The level of NO was determined using Griess reagents and method (Laudanska, 1970).

\section{Statistical Analysis:}

The data were represented as mean and standard deviation. Student's t-test was used to determine significant difference between the means. The $5 \%$ $(\mathrm{p}<0.05)$ level of significance was used to compare the means and S.D.

Table 1:

Comparison (Mean + S.D) of age, plasma Vitamin C and Vitamin E levels in smokers and non-smokers.

\begin{tabular}{|l|l|l|l|l|}
\hline Parameters & Smokers $(\boldsymbol{n}=\mathbf{2 8})$ & Non-smokers $(\boldsymbol{n}=\mathbf{3 0})$ & t-values & p-values \\
\hline Vitamin E $(\mathrm{mg} / \mathrm{dL})$ & $0.67 \pm 0.22$ & $0.77 \pm 0.25$ & 2.90 & $<0.05$ \\
\hline Vitamin C (mg/dL) & $0.63 \pm 0.25$ & $0.84 \pm 0.31$ & 4.70 & $<0.05$ \\
\hline Age (years) & $32.89 \pm 9.14$ & $34.14 \pm 9.45$ & 0.134 & $>0.20$ \\
\hline
\end{tabular}


Table 2:

The levels of NO and acute phase proteins in Nigerian cigarette smokers compare with non-smokers.

\begin{tabular}{|l|l|l|l|}
\hline Subjects & NO $(\mathrm{mM} / \mathrm{dL})$ & Alpha 2 macroglobulin $(\mathrm{g} / \mathrm{L})$ & Caeruloplasmin $(\mathrm{g} / \mathrm{L})$ \\
\hline Control $(\mathrm{n}=30)$ & $6.6+0.3$ & $2.01 \pm 1.48$ & $0.87 \pm 0.66$ \\
\hline Smokers $(\mathrm{n}=28)$ & $6.2+1.2$ & $2.14 \pm 1.05$ & $1.34 \pm 1.0$ \\
\hline T, p values & $1.25,>0.2$ & $4.33,<0.05$ & $1.00,>0.2$ \\
\hline
\end{tabular}

\section{RESULTS}

The average age for smokers participating in this study was $32.89 \pm 9.14$ years old as compared to $34.41 \pm 9.45$ years old for non-smokers, while the mean number of cigarette smoked daily was 13.66 \pm 8.87 sticks per day. Plasma concentrations of vitamins $\mathrm{C}$ and $\mathrm{E}$ were significantly lower while NO was not significantly reduced in the smokers compared with the controls. The level of alpha-2macroglobulin was significantly raised while caeruloplasmin was not significantly raised in smokers compared with controls.

\section{DISCUSSION}

The interrelationships of smoking, NO, micronutrient status and acute phase proteins are incompletely defined. Moreso, this is the first of such study in Nigeria. The smokers considered for this study had significant but modest deraged levels of acute phase proteins and micronutrient vitamins. This is consistent with their relatively young age $(32.89 \pm 9.14 \mathrm{yrs})$, few number of sticks smoked daily (13.66 \pm 8.87$)$ and brief smoking history (4-10 yrs).

It is known that cigarette smoking induces pulmonary inflammation, which is reflected in part by increased numbers of macrophages and neutrophils in the lungs of the smokers (Pryor, 1997). The hypothesis is that induced pulmonary inflammation (which is local) may affect circulating micronutrient status and immune functions. Also oxidants present in cigarette smoke and those generated by activated phagocytes is expected to create an oxidant antioxidant imbalance, which may adversely affect both micronutrient status and immune functions.

The level of NO in smokers considered for the present study was lower compared with the controls. The reason for observation could be due to mopping up of $\mathrm{NO}$ by antioxidants such as vitamins $\mathrm{C}$ and $\mathrm{E}$ as supported by the present study where the levels of these antioxidants are reduced. We found significantly reduced level of vitamin $\mathrm{C}$ in Nigerian smokers, which might be due to increased rate of use by oxidants generated by cigarette smoke. A study reported that nonsupplemented smokers have been estimated to have approximately three times the risk of a hypovitaminosis $\mathrm{C}$ as non smokers (Lykkesfeldt et al, 1997). Vitamin $C$ has been reported to enhance the chemotatic activity of neutrophils and lymphocyte transformation, possibly as a result of inhibition of myeloperoxidase- mediated iodination of proteins (Niki, 1991). Vitamin C has also been reported to decrease the damage induced by extracellular concentration of reactive bacterial oxidants (Nakao and Yasuett, 2000). Presumably, the net result of lower vitamin $\mathrm{C}$ levels in smokers would be to impair the antimicrobial properties of neutrophils and increase the risk for extracellular tissue damage by leucocytes-generated oxidants.

In our study, plasma level of vitamin $\mathrm{E}$ was a significantly reduced in smokers compared with non-smokers. In other study, plasma vitamin $\mathrm{E}$ was not significantly different in smokers compared with non-smokers (Stryker et al, 1988). Low level of vitamin $E$ in our subjects may be attributed to increased oxidation of plasma vitamin $E$ or increased passage of plasma vitamin $E$ to alveolar fluid where vitamin $\mathrm{E}$ is known to be rapidly oxidized to quinine form (Northrop-Cleves and Thurnham, 2006).

There are 1,015 organic free radicals in cigarette smoke which raises serum proteases, inactivates alpha-1-proteinase inhibitor, leading to emphysematous lesion and loss of lung elasticity (Hecht, 2002). Significantly raised level of alpha2-macroglobulin in cigarette smokers is a mechanism by the body to protect against cigarette induced lung damage. In our study, a higher level 
of caeruloplasmin was observed in smokers. Caeruloplasmin is an acute phase protein that transports $\mathrm{Cu}$, oxidizes $\mathrm{Fe}^{2+}$ to $\mathrm{Fe}^{3+}$, and also an antioxidant against lipid peroxidation (Hellman and Gitlin, 2002). Raised level of caeruloplasmin might be one of the strategies to reduce oxidants.

Several experimental and prospective epidemiological studies have shown association of elevated acute phase proteins, subclinical inflammation and cardiovascular diseases (Murat et al 2006). All of these risk factors are associated with increased oxidative stress in the vessel wall, which may contribute to cardiovascular diseases by several mechanisms. Others CVD have suggested that natural and synthetic anti-oxidants can prevent the development of cardiovascular diseases clinical end points (Halliwell, 1999).

It is the conclusion of the authors that because of low levels of vitamin $\mathrm{E}$ and vitamin $\mathrm{C}$ in our subjects, we advocate diet supplementation with vitamins $\mathrm{E}$ and $\mathrm{C}$ for those that must smoke cigarettes. This will reduce the progression of cardiovascular diseases through endothelial dysfunction and lipoprotein oxidation. More so, this study confirmed that inflammation is induced by cigarette smoking and this affects host immunity. Based on the conclusions above, the authors wish to advice cigarette smokers to quite the habit.

\section{Acknowledgement:}

This study is partially supported by University of Ibadan, Senate Research Grant (SRG/com/2000/38A).

\section{REFERENCES}

Alberg, A. (2002). The influence of cigarette smoking on circulating concentrations of antioxidant micronutrients. Toxicology 15: 180(2):121-137.

Dietrich M, Block G, Norkus E.P, Hudes M, Trabe M.G, Cross L. (2003). Smoking and exposure to environmental tobacco smoke decrease some plasma antioxidants and increase gamma-tocopherol in vivo after adjustment dietary antioxidant intakes. Amer. J Clin. Nutr. 77(1):160-166.

Duthie CG (1999). Determination of activity of antioxidants in human subject. Proceed. of Nutr. Sci. 58:1015-1020.

Fehily A.M, Philips K.M, Yarnell JW. (1980). Diet, smoking, social class and body mass index in the coronary Heart Disease Study. Am J. Clin. Nutr: 40:827-833.

Halliwell B, and Gutteridge JMC. 1995 The definition and measurement of antioxidants in $b$ iological systems. Free Rad. Biol. Med. 18: 125-128.

Halliwell B. (1999). Free radicals and antioxidants. Nutr. Rev. 52: 253-263.

Hellman, N.E. and Gitlin, JD. (2002). Ceruloplasmin metabolism and function. Annu Rev Nutr 22:439-58.

Hecht A (2002). Cigarette smoking and lung cancer: chemical mechanisms and approaches to prevention. Lancet Oncol 3: 461- 469.

Lykkesfeldt J, Lofts E, Nielsen JB, Poulsen HE. (1997). Ascorbic acid and dehydroascorbic acid as biomakers of oxidative stress caused by smoking. Amer. J Clin. Nutr. 65:959-963.

Martin A and Freit B. (1997). Both intracellular and extracellular vitamin $\mathrm{C}$ inhibit atherogenic modification of LDL by human vascular endothelial cells. Arterioscler. Thromb. Vasc. 17:1583-1590.

Murat A., Hasan C, Mustapa C, Pinar C and Mustafa G. (2006). Comparison of effects of smoking and smokeless tobacco "maras powder" use on humoral immune system parameters. Mediator of inflammation. 20: $1-4$

Nakao K and Yasuett T. (2000). Insulin resistance and endothelial dysfunction in smokers, effects of Vitamin C. Amer. J. Physiology, Heart and Circulatory Physiology. 279(3): 1172-1178.

Niki E. (1991). Action of ascorbic acid as a scavenger of active and stable oxygen radicals. Amer. J.Clin.Nutr.54:119-124.

Northrop-Clewes C.A and Thurnham D. I. (2006). Monitoring micronutrients in cigarette smokers. Clin Chim Acta 377(1-2):14-38

Pryor WA. (1997). Cigarette smoke radicals and role of free radicals in chemical carcinogenicity. Environ Health Perspect. 105 (supp14): 875-882.

Stryker WS, Kaplan LA, Stein EA, Stampfer MJ, Sober A and Weillett WC. (1988). The relation diet, cigarette smoking and alcohol consumption to plasma beta-carotene and alpha-tocopherol levels. Amer. J. Epidemiol. 127: 283-296.

Young IS and Wood JV (2001). Antioxidants in health and disease. J. Clin. Pathol. 2001, 54: 176-186. 